\title{
A TRANSFORMAÇÃO DO ESPAÇO URBANO NA CIDADE DE VIÇOSA, MINAS GERAIS ENTRE 1964- $1980^{1}$
}

\author{
Dayana Debossan Coelho²
}

\begin{abstract}
RESUMO: Este artigo discute o processo de urbanização em Viçosa, Minas Gerais. A década de 1970 funcionou como um "divisor de águas" na cidade, marcando a mudança quanto ao local de residência e de trabalho da população. A pesquisa teve como intuito identificar os eventos que contribuíram para o aumento do fluxo migratório em direção a Viçosa. Também se procurou destacar os projetos viários, como a construção da BR-120 que conectou Viçosa a Belo Horizonte. Constatou-se que a concretização da BR-120 buscou, sobretudo, adentrar o espaço de Viçosa, implicando o seu desenvolvimento urbano e regional e articulando-o à capital do estado e demais cidades mineiras. O setor imobiliário em Viçosa assumiu atividade de comando, o que conduziu à transformação do espaço urbano. A cidade sofreu profunda transformação econômica à medida que as atividades imobiliária e de construção civil se afirmaram e se expandiram, impulsionando a alteração dos setores da economia urbana.
\end{abstract}

Palavras-chave: Valorização do solo; urbanização; Estado; promotores imobiliários; mercado de terras.

\section{THE TRANSFORMATION OF URBAN SPACE IN VIÇOSA CITY, MINAS GERAIS BETWEEN 1964-1980}

ABSTRACT: This paper discusses the urbanization process of Viçosa, Minas Gerais. The decade of 1970 work as watershed for the city, it marked the changes in the residence and work places of the population. The research aimed identify the events that contributed for the increase of migration to Viçosa. It also tried highlight the road projects, as the built of BR-120 which connect Viçosa at Belo Horizonte. It was found that the built of BR-120 implied in the urban and regional development of Viçosa and it articulated Viçosa with the state capital and other cities of Minas Gerais. The real state industry took the command, which conducted the urban space transformation. The city suffered a deep economical transformation as the real estate and construction activities were strengthened and expanded, boosting the changing sectors of the urban economy.

Keywords: land valuation; urbanization; State, property developers; land market.

\footnotetext{
${ }^{1}$ Este trabalho representa uma versão modificada de um dos capítulos da dissertação "O direito à moradia: uma análise da provisão habitacional em Viçosa (MG) entre 1964-1986”, defendida em 2016. O apoio financeiro foi concedido pela Coordenação de Aperfeiçoamento de Pessoal de Nível Superior (CAPES).

2 Mestre pela Universidade Federal de Juiz de Fora. dayanadebossan78@gmail.com
} 


\section{INTRODUÇÃO}

A partir da década de 1970 o Brasil enfrentou profundas mudanças sociais, políticas e econômicas em decorrência da modernização conservadora do campo. Estava subjacente a esta modernização o aumento da produtividade, o maior aproveitamento da força de trabalho, a diversificação da produção e a substituição de homens por máquinas (mecanização). Apesar de ter legitimado a racionalidade técnica na agricultura, a modernidade trouxe dilemas a um país que não realizou os pressupostos básicos da revolução burguesa - como a reforma agrária. Além de não ter promovido transformações sociais, o processo de modernização foi conivente com a manutenção das velhas estruturas de poder, ou seja, com a concentração de terras "nas mãos" de poucos proprietários.

Os projetos de modernização conservadora foram colocados a cabo, sobretudo após o Golpe Militar quando a economia brasileira atingiu a posição de oitava no Produto Interno Bruno (PIB) do mundo, seu parque industrial alcançou proeminente grau de complexidade e diversificação e a agricultura adquiriu técnicas e uma rede de serviços que conectou o território nacional (BECKER e EGLER, 1994). Se por um lado, tal modernização engendrou um pujante processo de dinamização econômico-industrial, por outro, a maioria da população brasileira não teve acesso aos benefícios do crescimento econômico.

Com o surto modernizador, o plano viário do país teve um novo ímpeto. Para a integração do território foram construídos os alicerces de sua verdadeira fluidez. Neste momento, a economia objetivava atender um mercado consumidor em plena ascensão e as demandas do mercado externo. Segundo Santos (2005) é nesta ocasião, que o Brasil se torna grande exportador de produtos agrícolas e industrializados. Sobretudo, após a Segunda Guerra Mundial foram criadas as condições necessárias à integração do país: conexão das estradas de ferro e construção de estradas de rodagem - articulando as diversas regiões e pondo-as em contato com a região central.

O acesso ao mercado era uma proposta nítida do Estado, pois a abertura de vias rápidas atenuaria o processo de desvalorização do capital, diminuindo cada vez mais o tempo de giro no seu movimento cíclico. A articulação da rede de circulação promoveu maior eficiência na produção ao unir pontos estratégicos, tanto da oferta de matéria-prima e auxiliares, como de mercado, de produtos. Portanto, o espaço tonar-se fluido, permitindo que os fatores de produção, o trabalho, as mercadorias, o capital passem a ter grande mobilidade.

Em Minas Gerais, mais especificamente em Viçosa (município localizado ao norte da Mesorregião da Zona da Mata), foram criados planos e projetos de desenvolvimento urbano e regional na década de 1970, como foram os casos da construção da BR-120 (que ligou a cidade a Belo Horizonte) e das estradas vicinais da região. Neste artigo serão mobilizados esforços na discussão da criação desta rodovia e dos aspectos políticos, econômicos e sociais que caracterizavam Viçosa no período de 1964 a 1980.

Até o final da década de 1960, as cidades do interior da Zona da Mata de Minas Gerais permaneceram como núcleos inexpressivos. Viçosa não foge a esta realidade. Neste momento, sua paisagem ainda era marcada por grandes fazendas e sítios sendo o uso da terra predominantemente agrícola.

O movimento de ocupação da cidade se iniciou de forma incipiente pelos vales e pelas áreas planas ainda disponíveis. Foi a partir da década de 1970 que a ocupação se intensificou, quando a população urbana do município ultrapassou a 
rural. No final da década de 1960, a pequena produção foi favorecida pela nova divisão social do trabalho. Nesta época, ocorreu a expansão do regime de colonato das fazendas, o que contribuiu para a constituição do mercado de trabalho na área urbana de Viçosa.

Com o crescimento urbano de Viçosa verificado, sobretudo a partir de 1970, as edificações, que até então ocupavam principalmente os fundos dos vales da cidade, começaram a subir os morros abertos em loteamentos não só no entorno do centro, mas também na periferia. Este movimento modificou sensivelmente a forma dos vales, já que as antigas ruas passaram a ser vias coletoras de tráfego dos bairros que iam surgindo nas encostas.

É neste movimento de urbanização da cidade que a década de 1970 funcionou como um "divisor de águas", marcando a mudança quanto ao local de residência e de trabalho da população, processo que será analisado mais cuidadosamente no próximo item.

\section{O PROCESSO DE URBANIZAÇÃO NA CIDADE DE VIÇOSA}

O Brasil, como os demais países da América Latina, apresentou um rápido processo de urbanização no século XX, sobretudo, a partir da década de 1970 . Santos (2005), ao periodizar a urbanização brasileira, destaca a mudança quanto ao local de residência da população. Ele coloca que entre 1970 e 1980 ocorre uma inversão, na qual a população urbana supera a população total do país. A taxa de urbanização que era de $26,35 \%$ em 1940 salta para 68,86\% em 1980, ou seja, neste intervalo triplica a população brasileira, ao mesmo tempo em que a população urbana se multiplica por sete vezes e meia.

Para entender o processo de urbanização em Minas Gerais e particularmente o caso de Viçosa, Santos (2005) fornece dados importantes. Ao analisar o perfil demográfico do estado, ele destaca que entre os anos 1960 e 1970 ocorreu a segunda maior perda da população rural do Brasil e que as aglomerações com mais de 20 mil habitantes apresentaram um crescimento expressivo em sua população urbana. Baseando-se em dados estatísticos, o autor mostra que entre 1950 e 1980 há um aumento de 4,58 vezes da população urbana, ou seja, nesse período "[...] de cada cem novos urbanos, 77 se encontram em cidades e vilas com mais de 20 mil habitantes" (SANTOS, 2005, p. 80). Isso significa que a população urbana das aglomerações com mais de 20 mil habitantes cresceu mais rápido que a população total e que a população urbana do país.

Em decorrência do crescimento da pobreza na zona rural dos municípios da Zona da Mata, que recebeu durante a década de 1970 grandes levas de migrantes, Viçosa, que então possuía 25.784 mil habitantes, apresentava um comportamento demográfico similar às demais cidades do Brasil e de Minas Gerais. Isto é, apresentava um aumento representativo de sua população urbana, decorrente dos fluxos migratórios da área rural da cidade e do entorno. Neste aspecto, entre 19601970 houve um acréscimo de $84,26 \%$ em sua população urbana.

Um dos elementos que explica o fluxo migratório em direção a Viçosa foi a pavimentação e a ampliação da Avenida Professor PH. Rolfs em 1963 (antiga Av. Governador Benedito Valadares), que, além de ter fomentado a indústria de construção civil, se constitui como um "ímã" ao atrair a força de trabalho da região ${ }^{3}$. Esta avenida, desde então, passa a ser o principal eixo de ligação da universidade

\footnotetext{
${ }^{3}$ A pavimentação ocorreu na última gestão do ex-prefeito Raymundo Alves Torres (1959-1962). A inauguração da pavimentação e da iluminação se deu em 27 de janeiro de 1963 (PACHECO, 2015).
} 
com os bairros. É nessa medida que a articulação do centro funcional da cidade à universidade concorreu para o deslocamento geográfico do eixo de crescimento e valorização dos terrenos, agora direcionada para as áreas situadas próximas a Av. $\mathrm{PH}$. Rolfs e a universidade. Em Viçosa essas transformações urbanas enquadramse na dinâmica capitalista do uso do solo, que se estrutura visando construir "desenvolvimentos geográficos desiguais". O interesse, como discute Harvey (2004), é a acumulação do capital.

Outro componente responsável pelo crescimento populacional de Viçosa foi a federalização da Universidade Rural do Estado de Minas Gerais (UREMG) através do decreto $n^{\circ}$ 64.825, de 15 de junho de 1969 (COELHO, 2013) ${ }^{4}$. Reflexo da centralização do poder no âmbito da União e do processo de modernização conservadora, a Universidade aufere, neste momento, recursos financeiros para sua expansão física, incluindo a ampliação do seu quadro de funcionários/servidores. Enquanto isso, a cidade não conseguiu acompanhar a rápida urbanização e os problemas dela advindos. Conclui-se que apesar do afluxo significativo de recursos financeiros e humanos, Viçosa experimentou um crescimento econômico excludente.

Com a federalização e a criação de novos cursos de graduação e pósgraduação, ampliou-se a demanda por emprego, habitação e terras servidas ${ }^{5}$, intensificando a disputa fundiária nos locais mais próximos à Universidade, ou seja, na área central. Ribeiro Filho (1997), ao analisar a Formação do Espaço Construído em Viçosa, afirma que as construções e as ampliações do campus universitário (novas edificações, obras de pavimentação e paisagismo) conduziram à diversificação dos grupos sociais e fomentaram as atividades do setor de construção civil. Parte do fluxo migratório era constituída por camadas sociais com maior poder aquisitivo como os funcionários, servidores, professores da Universidade e estudantes e, outra parte pelas camadas populares que se deslocavam em busca de uma proposta de emprego. Portanto, a federalização foi um dos eventos catalisadores que possibilitou o despertar do espírito empreendedor dos capitalistas locais.

Internamente, ocorreu um grande incremento nas atividades de ensino e, sobretudo, de pesquisa na instituição. A federalização proporcionou o desenvolvimento de importantes inovações e avanços no conhecimento e tecnologia de produtos agrícolas de grande valor econômico para o país. Os trabalhos de pesquisa concentrados, inicialmente, nas áreas de economia rural, fitotecnia e zootecnia, possibilitaram, de acordo com Borges (2004), excelentes resultados nas cadeias produtivas do feijão, da soja e da avicultura. O milho híbrido, cuja prática agrícola se iniciou sem muito êxito no final dos anos 1950, continuou sua trajetória de crescimento na região até o término da década de 1960. A fase áurea do produto ocorreu graças à expansão das atividades de pesquisa e extensão nas áreas de produção vegetal e animal, sobretudo devido à colaboração da Purdue University, Indiana, USA ${ }^{6}$. Com isso, a atividade agrícola se reaqueceu e os mentores do

\footnotetext{
${ }^{4}$ De acordo com Ribeiro Filho (1997), o Banco Interamericano de Desenvolvimento (BID) solicitou à Universidade (para autorizar empréstimo ao Governo Federal) a elaboração de um Plano de Desenvolvimento Físico. Este plano foi aprovado pela Comissão Especial para a Execução do Plano de Melhoramento e Expansão do Ensino Superior (CETES) e pelo próprio BID e conduziu a expansão da instituição.

${ }^{5}$ Segundo Morales e Souza (2010, p. 1), terras servidas são “[...] aquelas dotadas de serviços e equipamentos necessários ao desenvolvimento das práticas diárias no meio urbano", ou seja, infraestruturas e serviços urbanos de saneamento básico (água tratada, esgoto, aterro sanitário) de segurança, saúde, educação, pavimentação etc.

${ }^{6}$ Ainda no final da década de 1950 , foi realizada uma parceria entre a Agência para o Desenvolvimento Internacional do Governo Norte-Americano - USAID, tendo a Purdue University, Indiana, USA, como sua representante e a Universidade Rural do Estado de Minas Gerais (UREMG). Juntas, iniciaram um programa de cooperação que teve como objetivo o intercâmbio de experiências, sendo que este resultou no estabelecimento dos primeiros cursos de pós-graduação em ciências agrárias no país (RIBEIRO FILHO, 1997; MELLO, 2002).
} 
projeto acabaram por organizar a primeira empresa privada brasileira dedicada ao desenvolvimento, produção e comercialização de milho híbrido, que persiste até o presente.

A agricultura, de um modo geral, experimentou um crescimento expressivo logo após a inauguração dos cursos de pós-graduação da Universidade. A base científica, estabelecida no início da década de 1970, criou as condições indispensáveis para a instalação e o crescimento da cadeia produtiva da carne de aves na região. A segurança obtida na produção e no processamento permitiu Viçosa responder, com sucesso, às demandas locais, regionais, nacionais e, presentemente, até do mercado externo (BORGES, 2004).

As iniciativas de pesquisa e desenvolvimento promovidas pela Universidade provocaram mudanças em relação às atividades agrícolas do município. O território rural constituído de pequenas propriedades, em sua maioria com área inferior a 50 hectares, característica da economia familiar, foi ampliado. Também houve mudança no perfil dos proprietários rurais. Até a década de 1970, a maioria era de moradores do campo. Após este momento, este perfil passou a ser alterado: poucos são os que residem na propriedade.

Através das exportações, Viçosa se tornou o polo criador e irradiador de inovações tecnológicas em relação às culturas de café, da citricultura, do milho e da cadeia produtiva de aves. Acresce-se o avanço da bovinocultura de leite, que saiu da condição de atividade de subsistência para um patamar empresarial - a bacia leiteira de Viçosa passou a ser autossuficiente e a produzir excedentes. Essa mudança deve ser creditada à parceria entre instituições públicas como a Universidade Federal de Viçosa (UFV), Empresa de Pesquisa Agropecuária de Minas Gerais (EPAMIG), Empresa de Assistência Técnica e Extensão Rural (EMATER), uma empresa privada - e, naturalmente, os produtores.

O Brasil, após o fim da Segunda Guerra Mundial, se torna grande exportador de produtos agrícolas e industrializados (SANTOS, 2005). Novas técnicas (como máquinas e insumos) surgiram e foram gradualmente incorporadas ao campo. A economia objetivava neste momento atender um mercado consumidor em plena ascensão e as demandas do mercado externo. Este evento ficou conhecido como modernização agrícola, lembrando que esta não se restringe apenas a técnica, mas engloba também as modificações ocorridas nas relações sociais de produção. Contudo, esta modernização se processou de maneira desigual e excludente, uma vez que, privilegiou alguns poucos agentes - Estados, produtores, latifundiários e empresas - em detrimento de outros tantos pequenos produtores familiares. A expropriação dos meios de produção dos trabalhadores, o empobrecimento das camadas populares do campo, com intenso êxodo rural e a expropriação fundiária foram algumas das consequências desta modernização.

A expansão do setor industrial e a modernização da agricultura tiveram impacto crescente na urbanização de Viçosa. A indústria da construção civil liderou a expansão econômica e contribuiu para grandes mudanças na cidade, sobretudo por meio do processo paralelo de urbanização precária. Este processo é referente à abertura de loteamentos nas periferias, em geral populares, onde não há infraestruturas ou as que existem são extremamente precárias: faltam vias de acesso e as existentes, às vezes, não possuem pavimentação, não estão instalados os serviços de energia elétrica (ou quando estão trata-se de ligação clandestina), água tratada, esgoto e limpeza urbana; muitas vezes não há linhas de ônibus que atenda o local; inexistem escolas, comércio, unidades de saúde e lugares destinados ao lazer. Estas condições conduziram a uma situação precária de habitabilidade. 
Analisando este período, El-Dine e Alves (2007) mostram que a federalização da Universidade levou à criação de vários loteamentos, cujo objetivo era abrigar as distintas camadas sociais. Dos loteamentos criados - transformados em futuros bairros da cidade - alguns visavam atender o público de maior renda como o localizado no bairro de Ramos e Clélia Bernardes; outros se destinavam à classe média, como os bairros João Braz, Betânia, Santa Clara, Santo Antônio e Silvestre; $\mathrm{e}$, finalmente, para atender as classes populares, foram reservados os bairros de Amoras e Nova Viçosa.

Além dos loteamentos, a federalização da universidade alavancou a economia urbana do município através do setor de comércio e serviços. Observou-se, na paisagem próxima a Avenida $\mathrm{PH}$. Rolfs, a instalação de pequenos restaurantes que serviam comida a quilo e de empresas prestadoras de serviços (copiadoras, lavanderias, papelarias etc.). Alguns locais passaram a abrigar bares, casas noturnas e escritórios. A área central foi se reestruturando em decorrência da atividade econômica, que, ao se transformar, transforma seu entorno em função das mudanças no uso do solo. A intensificação do uso da terra no centro urbano viçosense redefiniu a forma da cidade e instigou uma ordenação social e espacial da vida urbana.

Neste contexto, Viçosa transforma-se de forma radical: quase metade de seu território foi loteada por Antônio Chequer, que, além de empreendedor imobiliário, tornou-se prefeito e vereador da cidade em diversos mandatos. Por ter sido responsável pela criação de quase todos os loteamentos que foram fundados na cidade, a figura de Antônio Chequer se afirma na cena pública como empresário de sucesso e protetor dos interesses de Viçosa ${ }^{7}$.

O processo de estruturação e desenvolvimento do mercado de terras e habitação em Viçosa desencadeado a partir de fins dos anos 1960 deu origem, logo no início da década de 1970, a três setores residenciais (destinados às classes alta, média e baixa) distintos e funcionalmente integrados em relação à divisão técnica, econômica e social do espaço.

Vinculado a este movimento de valorização das terras, nasceram as pequenas empresas dos setores imobiliários e construtivos, como a Incorporadora Sena e Figueiredo Ltda, Construtora Delta Ltda, Construtora e Incorporadora Chequer Ltda, Elias Chequer \& Cia, Construtora José Chequer \& Cia Ltda., Edificadora de Construções Ltda., Mundial Ferragens Ltda - Santana e Irmãos, Construtora Carvalho \& Chequer e Âncora Empreendimentos Imobiliários (COELHO, 2012). Neste caso, é importante ressaltar que a Construtora e Incorporadora Chequer Ltda., Elias Chequer \& Cia, Construtora José Chequer \& Cia Ltda., Construtora Carvalho \& Chequer, Enfoque e Âncora Empreendimentos Imobiliários eram da família Chequer.

Estes setores, que passam a fazer propaganda intensa dos novos loteamentos nos jornais locais, aliados aos donos de terrenos (proprietários de pequenas fazendas e sítios ainda presentes na paisagem de Viçosa), tornam-se os principais responsáveis pela abertura de novas áreas para a venda e/ou aluguel e pelo incremento do mercado imobiliário na década de 1970.

É neste movimento de urbanização da cidade, ou seja, em um contexto de transformação e conversão do uso do solo, que nascem paralelamente os bairros de

\footnotetext{
${ }^{7} \mathrm{~A}$ respeito desse personagem Coelho e Chrysostomo (2015, p. 303) assinalam que ele "[...] exemplifica as práticas de capitalização do mercado de terras, ao se notabilizar como maior empresário da construção civil de Viçosa. Além disso, seu exemplo demonstra o empoderamento político que foi criado pela imagem propagandeada pela imprensa e legitimada nas várias campanhas eleitorais. Carregando a bandeira em prol dos menos favorecidos, 'dos marginalizados' e oprimidos, as imagens de Chequer esconderam os benefícios e privilégios conquistados por ele durante a sua trajetória de vida".
} 
classe média e as periferias urbanas. Aproveitando-se os recursos oferecidos pela cidade, a grande oferta de terras e a legislação maleável, os grupos imobiliários e setores da construção civil passam a capturar todos os recursos possíveis para ampliar seus lucros. Dentre esses recursos, uma legislação urbanística permissiva buscava atender os interesses de uma pequena parcela da população ${ }^{8}$.

Visando expandir o mercado de terras, os empresários imobiliários compravam terrenos por valores ínfimos localizados em fazendas e sítios antigos, como foram os casos da Fazenda "Coelha", da colônia agrícola Vaz de Mello e do sítio Santiago ${ }^{9}$. Deste mercado participaram vários agentes: o primeiro representado pelos herdeiros, que eram proprietários de parcelas desmembradas das grandes fazendas; com o tempo, os herdeiros alienaram estes imóveis para pequenos sitiantes; a partir, sobretudo da década de 1970, estes sitiantes repassaram os lotes para terceiros e para companhias imobiliárias (COELHO, 2013). O acúmulo de capital imobiliário por meio da atividade imobiliária explodiu, tendo em vista que a terra foi comprada por preços irrisórios.

A compra de terrenos em locais pouco valorizados contava com dois imperativos: drenar a renda urbana e desenvolver um mercado para atender as camadas sociais com nível de renda baixo. No primeiro caso, como as glebas incorporadas à malha urbana se situavam em áreas rurais, os capitais injetados nestes terrenos eram baixos (equipamentos, serviços de infraestrutura etc.), logo, apesar da possível fertilidade das terras, os poucos investimentos contribuíam para que os terrenos fossem baratos. No segundo, em função da valorização da área central da cidade, os proprietários fundiários e promotores imobiliários fomentam um mercado de terra para atender as camadas sociais, em geral ocupadas por migrantes e pobres.

As estratégias de compra e venda de terras empregadas pelos grupos mais capitalizados foram facilitadas quando os estabelecimentos financeiros se instalaram na cidade, como as agências bancárias do Banco Mineiro de Produção (1961), Banco do Brasil (1975), Caixa Econômica Federal (1975), Bradesco (1978), Banco Real (1978) e, mais tarde, Minas Caixa (1984). Como em muitas outras cidades, verificou-se que o crescimento urbano de Viçosa foi resultante da associação de diferentes capitais: o capital financeiro e os capitais imobiliário e fundiário. Compreende-se, assim, que o movimento de expansão geográfica dos diferentes capitais promoveu a territorialização de várias áreas da cidade (centrais e periféricas), marcando uma apropriação oligopolista do solo (COELHO, 2013).

As atividades imobiliária e de construção civil assumiram uma função de comando na produção e reprodução espacial viçosense, articulando e subordinando outras parcelas do espaço. Viçosa sofre, portanto, profunda transformação econômica à medida que aqueles ramos se afirmam e se expandem na cidade, impulsionando a alteração dos setores da economia urbana - com isso, a relevância da esfera primária cai expressivamente.

Entende-se aqui produção e reprodução do espaço a partir da perspectiva apresenta por Carlos (2012). Para entender as relações sociais é necessário pensar na dimensão espacial contida nas mesmas, ou seja, compreender a espacialidade como inerente a existência da sociedade. Tal ótica

\footnotetext{
${ }^{8}$ Segundo Almeida (1983), os agentes modeladores do solo urbano (incorporador, construtor, corretor e especialista em viabilidade técnica e econômica) possuem um papel importante nas cidades de economia capitalista, onde as instituições jurídicas estão amarradas às leis que determinam a aquisição da propriedade privada e as deliberações do jogo de mercado. ${ }^{9}$ Tais lugares futuramente se converteram em bairros periféricos: Nova Viçosa, Amoras e Novo Silvestre, respectivamente.
} 
[...] aponta para a ideia de que a sociedade, ao produzir-se, o faz num espaço determinado, como condição de sua existência, mas através dessa ação ela também produz, consequentemente, um espaço que lhe é próprio e que, portanto tem uma dimensão histórica com especificidades ao longo do tempo e nas diferentes escalas e lugares do globo (CARLOS, 2012, p. 53).

Esse enfoque aconselha considerar a reprodução da sociedade em seu todo por meio da produção/reprodução do espaço. A produção do espaço em Viçosa revela como os atores das pequenas cidades criam estratégias para ser apropriar do solo tendo em vista os processos de urbanização capitalista que se desenvolvem em outras escalas espaciais. Assim, como sede regional do processo de acumulação, esta pequena cidade assume um papel dinâmico na produção do espaço global (nacional e internacional). Contribui para tanto a expansão do conhecimento técnicocientífico (desenvolvendo a economia local) a partir da federalização da UREMG. A grande concentração cumulativa de funções e a demanda acadêmica fazem com que a universidade desenvolva uma rede de relações com o restante do país através da existência de seus inúmeros campus de pesquisa e também das parcerias efetuadas com as universidades internacionais.

Tal processo singularizou-se devido a atuação de alguns agentes, entre eles, o Estado, os promotores imobiliários e os proprietários fundiários. A história socioespacial de Viçosa revela a influência da federalização da UREMG nos processos de valorização do espaço e da formação das periferias na cidade.

O Estado, em Viçosa, teve grande influência na constituição de um mercado imobiliário urbano, já que, através de suas ações e regulamentos, ele interferiu na formação do preço da terra. A prática espacial do Estado geralmente é caracterizada pela observação e interação de alguns aspectos visando à regularização do solo: a localização do terreno, o acesso aos lugares ditos privilegiados (shoppings, centros de saúde e de lazer, áreas verdes etc.), à infraestrutura (água, luz, esgoto, ruas e estradas asfaltadas, telefone, vias de circulação) e à privacidade. Portanto, o que vai determinar o preço da terra são a existência e a intensidade dessas materialidades e a sua distribuição em determinada parcela no espaço urbano global (CARLOS, 1994; $2001 ; 2011$ ).

No próximo tópico, ver-se-á que a localização de parte das classes sociais em Viçosa se deu nas imediações da BR-120, que passou a influenciar o preço da terra na cidade. O debate se inicia no ano de 1964, quando são publicadas as primeiras notícias reivindicando o asfaltamento das estradas da região nos jornais locais e termina em 1973 quando a BR-120, que compreende a extensão de 47,7 quilômetros de pavimentação asfáltica ligando Viçosa a Belo Horizonte, foi finalmente inaugurada. Nesse sentido, apresentar-se-ão as principais notícias propaladas no período mencionado.

\section{CONSTRUÇÃO DA BR-120: A VALORIZAÇÃO DE TERRAS NA CIDADE}

O crescimento urbano e econômico em Viçosa exigiu novas redes técnicas, requisitos para a ampliação do acúmulo e da liquidez de excedentes. Dentre estas redes estava à construção da BR-120, considerada importante para o escoamento da produção da região (aves, batata inglesa, café, cana-de-açúcar, citricultura, feijão, 
milho híbrido, soja e tomate) e seu progresso sociocultural, além de se integrar às novas rodovias do sistema viário da rede Federal.

Buscando impulsionar a indústria de construção civil e proporcionar a construção das estradas vicinais da região, sobretudo a BR-120 que ligaria Viçosa à capital mineira, foi efetuada uma aliança entre os setores privados da economia e o Estado. O discurso para promover esta operação se pautava na melhoria da política urbana. Entretanto, se camuflava que a construção das estradas resultava de interesses imobiliários, uma vez que as intervenções urbanas são importantes instrumentos de valorização do solo urbano.

A justificativa para barganhar a construção da BR-120, a melhoria de estradas e a inserção de asfalto em algumas localidades se pautavam na categoria de "cidade universitária". Exemplo disso foi à construção de uma narrativa de apelo na qual a cidade internacionalizava-se através do 'mundo científico' propalado pela Universidade. Sob este aspecto, as lideranças locais se expressaram no principal veículo de comunicação da época: "[...] nossa cidade cresce a olhos vistos, internacionaliza-se, impõe-se no conceito de mundo científico, tanto brasileiro quanto estrangeiro" (A CIDADE, 1964, s/p, grifos nossos).

O debate reivindicando o asfaltamento das estradas da região se inicia no ano de 1964, quando são publicadas as matérias nos jornais locais. A primeira notícia propalada pelo jornal $A$ Cidade foi sobre o isolamento de Viçosa perante as demais regiões, nela observa-se a preocupação das lideranças locais em integrar a cidade às regiões do país:

Viçosa é cidade insulada e esta característica the tem causado prejuízos e danos imensuráveis e irreparáveis. A cidade sem estradas é cidade segregada de convívio adequado, um local isolado do contato necessário no mundo dinâmico de hoje. [...] De braços cruzados, estaremos fadados a viver, eternamente isolados dos grandes centros (A CIDADE, 1964, s/p, grifos nossos).

Os adjetivos que os redatores dos jornais atribuem à cidade - "sem estrada", "insulada", "isolada", "segregada" - caracteriza a rede viária de Viçosa no contexto da década de 1960. A paisagem da cidade ainda era marcada por grandes fazendas e sítios (sobretudo com cultivos de café), sendo o uso da terra predominantemente agrícola. Durante toda a década de 1960, a população ainda era rural (PREFEITURA MUNICIPAL DE VIÇOSA, 2014).

$\mathrm{Na}$ ocasião, o redator ainda faz um apelo às autoridades intermunicipais no sentindo de fortalecer a luta de Viçosa pelo asfaltamento das estradas a das demais cidades: "[...] uma estrada de alta qualidade não seria apenas de interesse local. As cidades vizinhas também se beneficiariam e assim elas também devem ser convidadas a cerrar fileiras ao nosso lado no justo reclamo de um direito a toda a região" (A CIDADE, 1964, s/p).

Ainda em 1964, outra matéria foi publicada solicitando ao Governo do Estado que se pavimentasse a rodovia que ligaria Juiz de Fora a Belo Horizonte, através de Ubá, Viçosa e Ponte Nova (BR-120). O jornalista dizia: "[...] grande número de autoridades [...] ficarão estarrecidas e dificilmente compreenderão como é possível deixar-se uma Universidade Rural e uma cidade como Viçosa, assim isolados dos grandes centros urbanos" (ibid., s/p), pois além do isolamento físico, havia também o comunicativo, uma vez que o sistema telefônico era muito precário.

Em 1966 uma reportagem registrou as contínuas promessas das autoridades governamentais, as obras enfim aceleram-se de tal modo que se podia esperar a 
inauguração em julho daquele ano do trecho MG 56, entre Ouro Preto e Ponte Nova (A CIDADE, 1966, s/p). O relator ratificou o asfaltamento do trecho Ponte Nova Viçosa e disse que possantes máquinas, importadas dos Estados Unidos, começariam a "rasgar" a rodovia. Acrescentou também que, após este momento, Viçosa se ligaria à Ubá - o que vale dizer à Leopoldina, à rodovia Rio - Bahia e à Juiz de Fora - e em seguida, às estradas Viçosa - Pôrto Firme e Piranga - Lafaiete. Por fim, esta seria a estrada direta para Belo Horizonte.

Uma matéria denominada Asfaltamento em 1967 chama atenção. Nela o engenheiro Eliseu Resende, diretor do Departamento de Estradas e Rodagem (DER) de Minas Gerais, revelou diversos aspectos do plano rodoviário do estado em um discurso pronunciado no Palácio da Liberdade. Quando houve o pronunciamento do engenheiro, vários contratos para construção de rodovias já haviam sido assinados, porém, segundo o redator, nenhuma referência foi feita a "acalentada" estrada que liga Viçosa à Ponte Nova. Procurado pelo reitor da Universidade Rural do Estado de Minas Gerais (UREMG), o engenheiro informou que havia ocorrido um lapso de sua parte. Eliseu Resende assegurou ao reitor que os trabalhos prosseguiam normalmente e que no final do ano seria aberta a concorrência pública para a pavimentação. Se posicionando em relação ao asfalto, o jornalista disse:

Não se desconhece que o plano rodoviário é gigantesco e que quase todo o Estado clama por rodovias pavimentadas. Temos que lutar pela nossa cidade, pela nossa região. Já não se faz necessário tentar justificar a importância da complementação do anel rodoviário da BR3. Ligada Ponte Nova a Ubá, através de Viçosa, completo estará o anel, cuja importância econômica é meridiana (A CIDADE, 1966, s/p).

Diante do apelo da universidade e das lideranças locais, o deputado Edgard Vasconcelos recebeu do DER um ofício em 06 de junho de 1967, escrito pelo engenheiro Eliseu Resende, no qual constava: "[...] acusando recebimento de sua solicitação com referência a rodovia Ponte Nova - Viçosa, apraz-me comunicar-lhe que transmiti ao Departamento de Estradas e Rodagem de Minas Gerais o apêlo no sentido de que as obras da referida rodovia sejam intensificadas" (A CIDADE, 1967, $\mathrm{s} / \mathrm{p})$.

Reunindo quinze prefeitos beneficiados pela MG-22 (que une Viçosa a Ponte Nova) o Encontro Regional de Prefeitos da Zona da Mata, ocorrido em 1968, mencionou a importância econômica e sociocultural de tal estrada. O escritor assinala que no setor econômico o documento do encontro abarca o potencial agropecuário e industrial da região e descreve as principais culturas e criações das indústrias de ração e laticínios. No setor sociocultural, a Zona da Mata é apresentada como uma das regiões mais privilegiadas do Estado, destacando-se dois centros universitários de grande importância: Juiz de Fora e Viçosa (FÔLHA DE VIÇOSA, 1968, s/p).

De 1968 a 1970, nenhuma matéria foi publicada sobre a pavimentação. Apenas em 1971 o assunto volta a ocupar espaço nos jornais. Foi divulgada neste ano a reportagem com a seguinte chamada: $O$ asfalto chega a Viçosa. Nela, o jornalista foi enfático ao afirmar que a cidade acabava de obter mais uma vitória em sua marcha para o progresso, já que, finalmente, o trecho Ponte Nova - Viçosa havia sido concluído. Ele também reiterava que, durante muitos anos, os políticos e entidades diversas procuraram levar ao conhecimento do Governo a necessidade e o valor que representava para a economia do município a ligação asfáltica Viçosa - Ponte Nova - Belo Horizonte (FÔLHA DE VIÇOSA, 1971). 
Um dos trechos de mais difícil trânsito, pelas suas inúmeras curvas e elevações, o de Viçosa a Coimbra (município da microrregião de Viçosa), foi transformado em uma estrada de fácil acesso. Os trabalhos de terraplanagem estavam sendo feitos pela Attica Engenharia Ltda., de Belo Horizonte. O DER-MG esperava, com todos os recursos estaduais, concluir, dentro do menor prazo, a ligação Ponte Nova, Viçosa, Cataguazes, passando por Teixeiras, Viçosa, Coimbra, Visconde do Rio Branco, Guidoval e Cataguazes, atingindo nesta cidade novo trecho asfáltico que ligaria a Rio-Bahia. Esta estrada, de acordo com o redator, seria a grande propulsora do progresso da Zona da Mata (ibid., 1971).

A inauguração da tão esperada BR-120 ocorreu em 29 de maio de 1973. Na Figura 1 vê-se uma multidão e também imensa fila de veículos deixando a Avenida Professor P. H. Rolfs (antiga Av. Governador Benedito Valadares) no dia da inauguração da pavimentação asfáltica de 47,7 quilômetros da BR-120.

Figura 1. Dia da inauguração da pavimentação asfáltica da BR-120

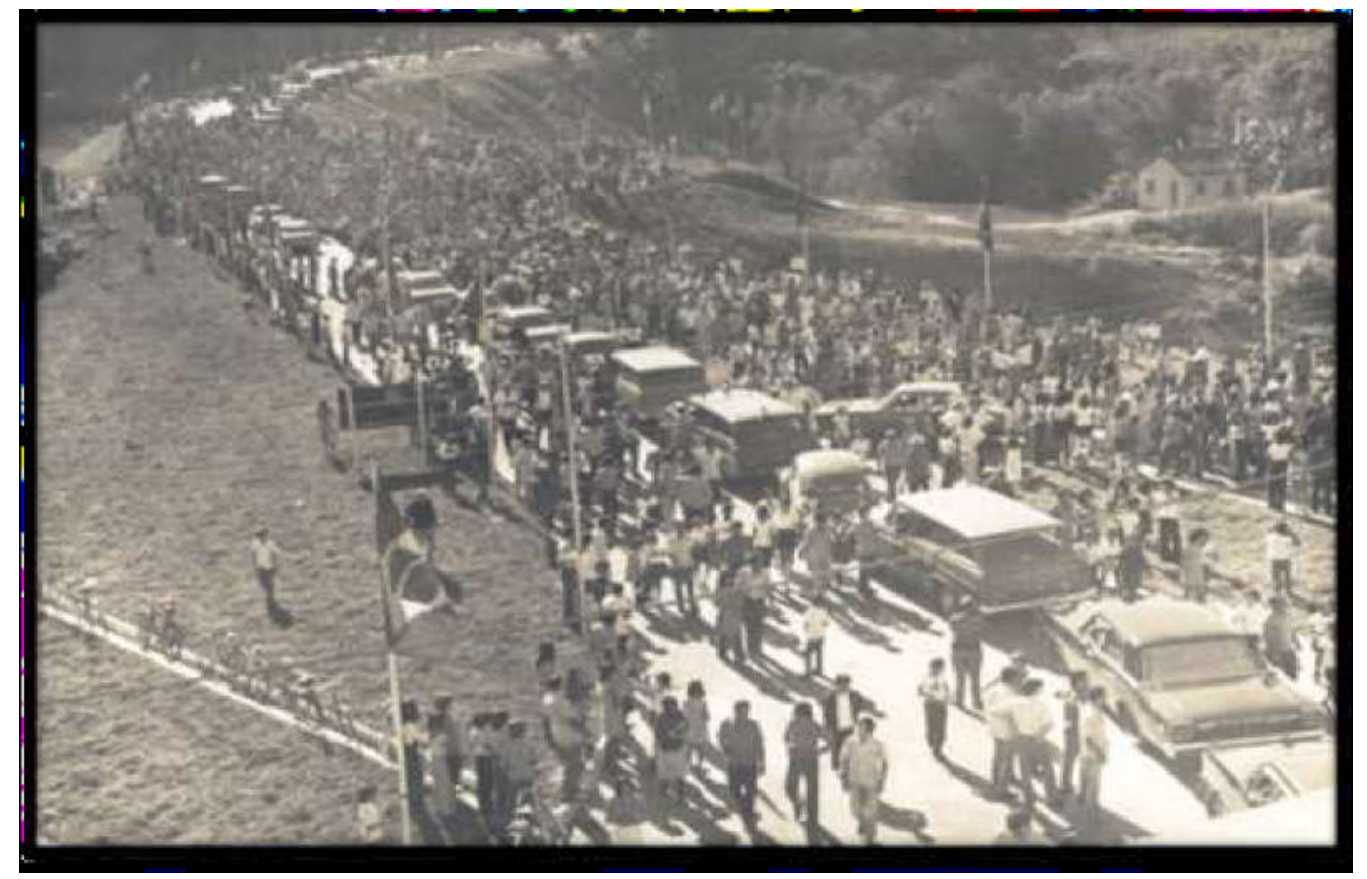

Fonte: Blog o passado compassado de Viçosa (2014).

A BR-120 articulou a cidade por via asfaltada aos principais pontos do país ${ }^{10}$, no seu trecho urbano, ganhou a denominação de Avenida Castelo Branco. Segundo Silva (2011, p. 48), a construção desta rodovia "[...] teve enorme influência no traçado da cidade, já que constituiu uma ligação rápida e direta com o distrito de Silvestre, introduzindo um novo vetor de expansão horizontal". Com a chegada da BR-120, abriu-se um novo vetor de crescimento na cidade, abrangendo a região dos

${ }^{10}$ Distância de Viçosa às cidades: 60 km até Ubá; 225 km até Belo Horizonte; 180 km até Juiz de Fora (CRUZ, 2012). 
bairros de João Braz e Santo Antônio (Figura 2), fazendo com que Silvestre se integrasse à sede do município, constituindo atualmente uma única mancha urbana. Desse modo, a construção dessa via imprimiu outra centralidade à cidade com implicações na valorização da terra urbana.

Figura 2. Avenida Castelo Branco perpassando alguns trechos do bairro Santo Antônio

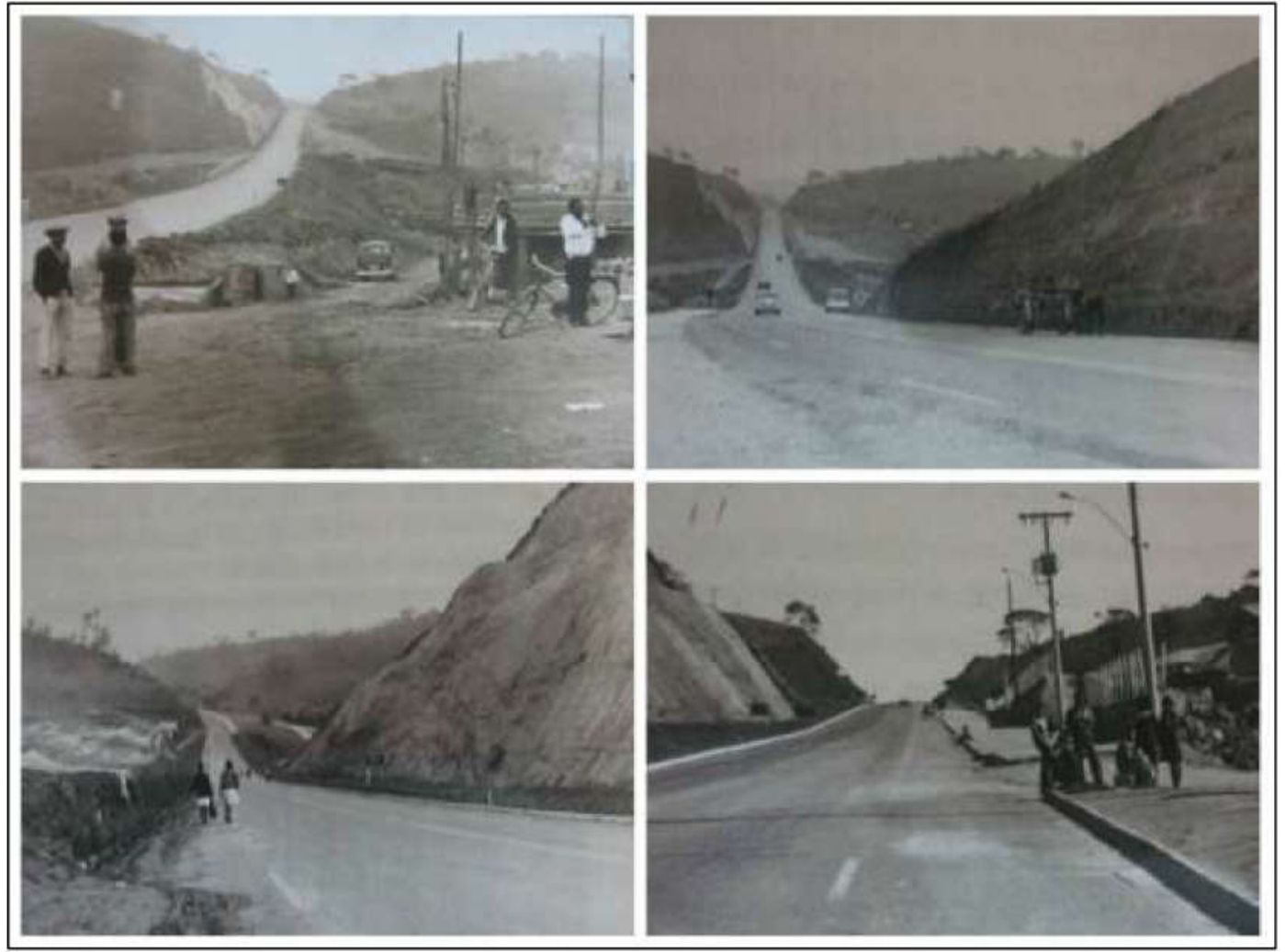

Fonte: COSTA, HOLLERBACH E BIFANO, 2011.

O Estado, ao investir na abertura de uma estrada, promoveu uma transformação no preço dos terrenos e imóveis da cidade. Assim, a orientação dos investimentos públicos é um dos principais fatores de valorização imobiliária (MARICATO, 1997). Em Viçosa, o preço das glebas passou a ser diferenciado em função da sua localização, ou seja, quanto maior a proximidade dos lotes às margem da BR-120 mais caros eram os mesmos. A acessibilidade da BR-120, recémconstruída, foi um dos elementos centrais para a valorização dos lotes (Figura 3). Os lotes de Nova Viçosa eram o que apresentavam o menor preço, ou seja, eram cerca de dez vezes mais barato do que os lotes do bairro Santa Clara. O que justifica o preço dos lotes em Santa Clara, apesar da BR-120 não atravessar o bairro, é sua inserção na área central da cidade.

A instalação dos primeiros serviços de infraestrutura realizados nos bairros Santo Antônio, Santa Clara, João Braz e Silvestre foram cruciais para capturar a renda do solo. Pode-se dizer que a partir da rodovia ocorreu um processo de valorização de áreas na esteira da abertura da Avenida Castelo Branco. Com isso, nova frente de investimentos imobiliários vem a reboque das facilidades proporcionadas pela construção de infraestrutura que valorizou o solo. Pode-se dizer, assim, que as lideranças políticas locais em parceria com os proprietários fundiários e o setor construtivo fomentaram o crescimento do mercado imobiliário. 
Figura 3. Localização da BR-120 em relação aos bairros de Viçosa (MG)

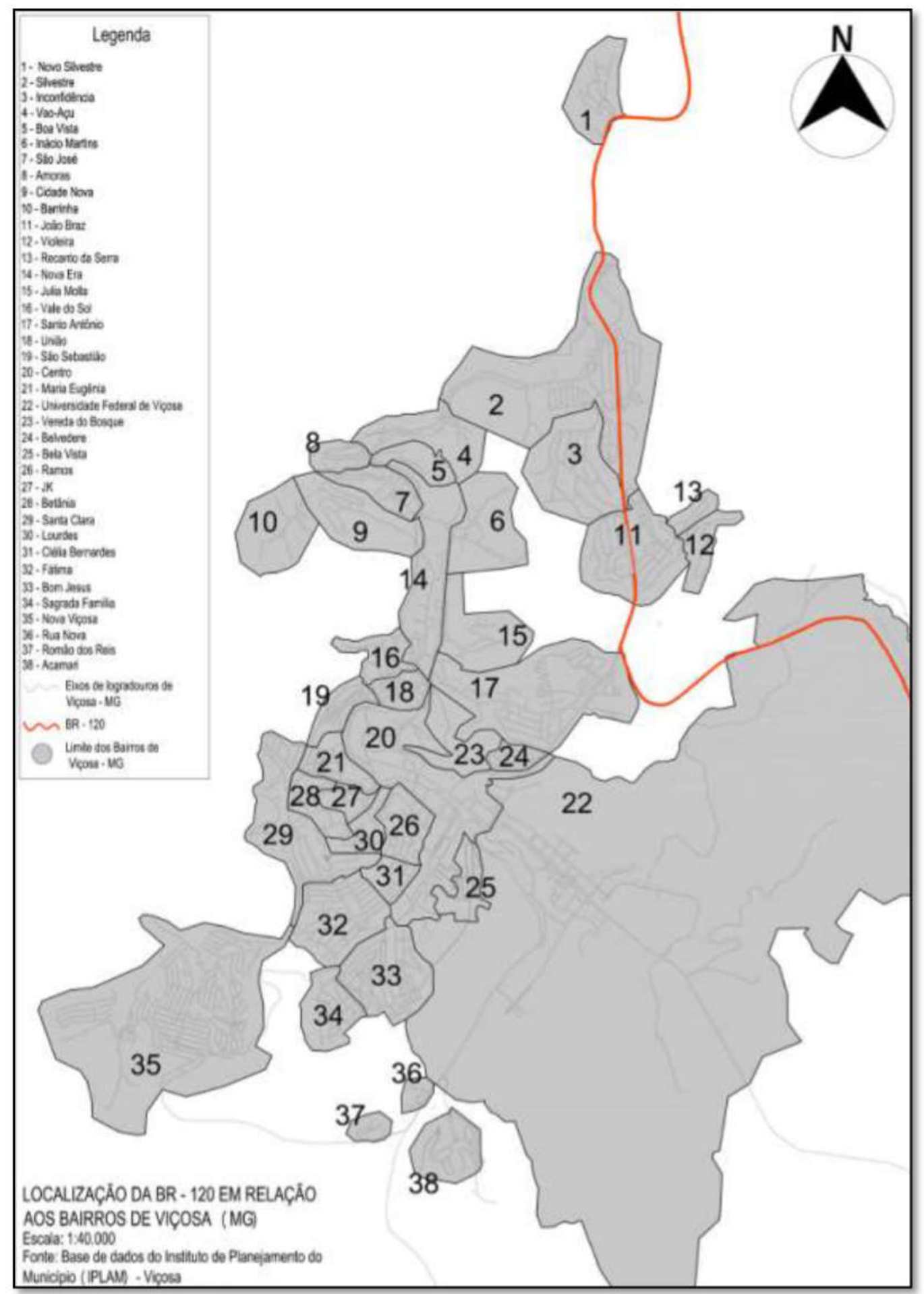

A BR-120 passou a ser acesso para a MG-280, que liga Viçosa a Paula Cândido, atravessando inúmeras comunidades rurais. Em 1978 ocorreu a complementação do asfaltamento das estradas vicinais da região, abarcando os seguintes trechos: Amparo da Serra, São Miguel do Anta e Pedra do Anta - 
Teixeiras, na extensão da BR-120 (FÔLHA DE VIÇOSA, 1978). O investimento nestas estradas articulou Viçosa a alguns municípios da sua microrregião.

Outras estradas foram asfaltadas em 1978, como a MG-329 no trecho Santa Cruz do Escalvado e nas interligações entre Amparo da Serra - Oratórios, Zito Soares - Piedade de Ponte Nova e Santo Antônio do Grama - Jequeri e a rodovia MG-262 no trecho Diogo de Vasconcellos (FÔLHA DE VIÇOSA, 1978). Estas rodovias conectaram Viçosa a uma parcela do espaço do estado de Minas.

O empenho dos setores públicos ao investir na BR-120 atraiu parte da riqueza social gerada que, por sua vez, foi canalizada e acometida nos estabelecimentos de condições gerais de produção, englobando, além de redes de comunicação, a de energia elétrica. Com isso, o preço e o uso da terra foram redefinidos estabelecendo, assim, distinções locais de renda, de classe e de uso.

Os proprietários fundiários captaram parte da mais-valia extraindo renda da terra. Portanto, uma das estratégias empregada pelos agentes locais, para ampliar sua margem de lucro com a venda dos terrenos, foi à inserção diferenciada do mercado de terras de parcelas do território da cidade, a exemplo dos lotes vendidos nos bairros João Braz, Santo Antônio e Silvestre.

Acredita-se que o sistema rodoviário, implantando em Viçosa e nas cidades vizinhas através da BR-120, foi inspirado no planejamento regional do Estado. Durante a ditadura militar, a formulação de uma política de desenvolvimento urbano não podia prescindir de uma ótica regional, indutora do avanço capitalista no país. $O$ principal objetivo daquele planejamento foi promover o desenvolvimento articulando à lógica econômica e social hegemônica a partir de políticas integradas territorialmente, visando diminuir o mosaico de desigualdades entre as regiões e intra-regiões. Duas políticas de grande envergadura foram as de integração nacional e regional, as quais buscaram criar, além de outros dispositivos, uma malha de circulação importante à integração física do território nacional e, de forma correlacionada, a unificação de mercado.

O sistema rodoviário de Viçosa, por exemplo, foi concebido de maneira a dinamizar umas das peculiaridades inerentes ao planejamento regional, que é a relação inter-regional. O programa de integração nacional traçou as coordenadas do sistema rodoviário federal, identificando-as pelas letras "BR" seguidas de um número, como foi o caso da BR-120. A construção desta rodovia constituiu poderosos elementos de articulação do território nacional, estadual e regional. A criação de alguns bairros (como João Braz e Silvestre) e a expansão de outros (como Santo Antônio) ao longo da BR-120 permitiram um aumento da zona de influência da rede urbana de Viçosa, ao passo que ocorreu um novo alinhamento à capital estadual.

Também se pode entender a BR-120 a partir dos fixos e fluxos que constituem o espaço geográfico. Segundo Santos (2014), os elementos fixos são econômicos, sociais, culturais e religiosos, como pontos de serviço, pontos produtivos, casas de negócios, hospitais etc. Os fluxos são o caminho de produtos, serviços e informações entre os fixos, como estradas, rotas áreas, internet, enfim, formados por componentes que possuem mobilidade, isto é, podem atuar em diferentes espaços. Desse modo, os fixos emitem fluxos que se constituem em movimentos entre os fixos.

No que se refere às infraestruturas e benfeitorias adicionadas ao solo, a BR120 funcionou como um fixo que se estruturou para atender às implicações externas (escoamento da produção). Numa economia em que a circulação ganha um papel preponderante, a rodovia proporcionou maior fluidez, sobretudo ao espaço 
viçosense. As inovações técnicas no sistema viário, como o asfaltamento das estradas vicinais da microrregião de Viçosa e a BR-120 (que conectou a cidade aos principais pontos do país), se constituíram como fixos permitindo os fluxos atuarem em escala local, regional e nacional.

\section{CONCLUSÃO}

O Estado, por meio de seus instrumentos legais, produziu grandes mudanças nos usos e funções dos lugares citadinos, reproduzindo a hierarquia desses lugares no conjunto de Viçosa. Ao direcionar os investimentos em infraestrutura, intensificaram-se as desigualdades na cidade, interferindo de modo acentuado nas formas de apropriação do espaço, uma vez que produziram um processo de valorização diferencial do solo. Assim, a distribuição do solo foi calcada nos usos que gerassem os mais altos lucros possíveis graças a sua utilização empreendedora.

O setor imobiliário em Viçosa assumiu atividade de comando, o que conduziu à transformação do espaço urbano (conversão da terra rural em urbana, intenso parcelamento do solo). A Construtora e Incorporadora Chequer Ltda., Elias Chequer Cia, Construtora José Chequer \& Cia Ltda., Construtora Carvalho \& Chequer, Enfoque e Âncora Empreendimentos Imobiliários tornaram-se os principais responsáveis pela abertura de novas áreas para a venda e o aluguel. Estes atores transformaram grande parte do território do município em área urbana no período de 1970 a 1980, lançando no mercado de imóveis diversos bairros.

O processo de urbanização na cidade foi submetido ao primado das leis da acumulação capitalista. A cidade se consolida como o lugar, por excelência, dos negócios. Sua dimensão geográfica evidencia-se em um arranjo espacial expresso na comercialização de frações de áreas (o espaço urbano em fragmentos). A indústria da construção civil foi então o "carro-chefe" desse processo. Ela colaborou, através da dinamização do comércio, para a absorção de força de trabalho, a abertura de inúmeros loteamentos na cidade e a construção de edifícios destinados aos mais variados usos.

Constatou-se que a concretização da BR-120 buscou, sobretudo, adentrar o espaço de Viçosa, implicando o seu desenvolvimento urbano e regional e, por fim, articulando-o à capital do estado e demais cidades mineiras. A abertura de vias de acesso também refletiu a real intenção do Estado: integrar o território para promover a unificação de mercado e, consequentemente, o desenvolvimento do país.

A construção da rodovia reduziu os custos de transportes. Além de intensificar a circulação dos fatores de produção e da valorização do espaço em si, os meios de transportes se tornaram, também, o meio de acelerar a exploração pelo capital do trabalho e dos trabalhadores. Todos estes aspectos refletiram a capacidade geográfica do Estado como grande agente produtor do espaço, principalmente por meio de suas políticas de ordenamento territorial.

\section{REFERÊNCIAS}

\section{FONTES PRIMÁRIAS}

ARQUIVO PÚBLICO MINEIRO. Jornais Avulsos Rolo 128. Fôlha de Viçosa. Viçosa, Minas Gerais, 1963-1978. 35 mm. Microfilme. 
BRASIL, MINAS GERAIS, VIÇOSA. Acervo do jornal A Cidade, sala de registros, 1961-1967, s/p.

BRASIL, MINAS GERAIS, VIÇOSA. Prefeitura Municipal de Viçosa, MG. A cidade. Da Ermida à Urbe. Disponível em: <http://www.vicosa.mg.gov.br/a-cidade/daermida-a-urbe>. Acessado em: 12 maio 2014.

BORGES, J. M.; SABIONI, G. S. (Org.). Cópia do relatório do chefe da comissão de construção da Escola Superior de Agricultura e Veterinária do estado de Minas Gerais (ESAV), Eng. João Carlos Bello Lisboa, ao secretário de agricultura Djalma Pinheiro Chagas. Viçosa: Universidade Federal de Viçosa (UFV), 2004, 89p.

\section{FONTES SECUNDÁRIAS}

ALMEIDA, R. S. A. Alternativas da promoção imobiliária em grandes centros urbanos: o exemplo do Rio de Janeiro. In: VALLADARES, L. P. (Org.); SANTOS, C. N. F.; ROLNIK, R.; BONDUKI, N. G. e ALMDEIDA, R. S. (Coord.). Repensando Habitação no Brasil. Série Debates Urbanos. Rio de Janeiro: Zahar S.A., v. 3, 1983, p. 169-190.

BECKER, B. K. e EGLER, C. A. G. A. emergência do Brasil como potência regional na economia-mundo. In: Brasil: uma nova potência regional na economiamundo. Rio de Janeiro: Bertrand Brasil, 1994, p. 123-168.

CARLOS, A. F. A. A Reprodução do espaço urbano. In: A (Re) Produção do espaço urbano. São Paulo: Editora da Universidade de São Paulo, 1994, p. 83179.

. Introdução. In:

Espaço-Tempo na metrópole: a fragmentação da vida cotidiana. São Paulo: Contexto, 2001, p. 11-44.

A cidade. São Paulo: Contexto, 2011, 98p.

Da "organização" à "produção" do espaço no movimento do pensamento geográfico. In: A produção do espaço urbano: agentes e processos, escalas e desafios. CARLOS, A. F. A.; SOUZA, M. L.; SPOSITO, M. E. B. (Org.). São Paulo: Contexto, 2012, p. 53-73.

COELHO, D. D. Nova Viçosa: a "menina dos olhos" do mito Antônio Chequer. Encontro Nacional de História do Pensamento Geográfico e I Encontro Nacional de Geografia Histórica, 3, 2012, Rio de Janeiro. Anais..., Rio de Janeiro, UFRJ, 2012, cd-rom.

Da fazenda ao bairro: a construção de uma Nova Viçosa (1970-2000), 2013, 123p. Monografia em Geografia (Trabalho de Conclusão de Curso). Curso de Geografia. Departamento de Geografia, Universidade Federal de Viçosa, ViçosaMG, 2013. 
COELHO, D. D. CHRYSOSTOMO, M. I. J. Estratégias imobiliárias e a construção do "mito" do pai dos pobres na produção dos bairros periféricos de Amoras e Nova Viçosa (1970-1990). Ra' e Ga 0 espaço geográfico em análise - Programa de PósGraduação em Geografia da UFPR, Paraná, v. 33, p. 277-306, 2015.

COSTA, R. P. A.; HOLLERBACH, J. D. G.; BIFANO, A. C. S. Bairro Santo Antônio: Relatos e Histórias de um Cantinho de Viçosa-MG. In: BIFANO, A. C. S. e LELIS, C. A. S. (Org.). Viçosa: Unidade Interdisciplinar de Estudos em Desenvolvimento Humano e Social, 2011, 29p.

CRUZ, T. A. (Coord.). Retrato Social de Viçosa IV. Viçosa, MG: CENSUS. Editora UFV, 2012, 88p.

EL-DINE, L. R. Z. E.; ALVES, N. C. A Voz dos Esquecidos: Memória Oral sobre o surgimento da periferia de Viçosa durante o século XX. In: Encontro Regional Sudeste de História Oral, 7, 2007, Rio de Janeiro. Anais..., Rio de Janeiro, FIOCRUZ, 2007, cd-rom.

HARVEY, D. Espaços de esperança. São Paulo: Edições Loyola. Brasil, 2004, 382p.

MARICATO, E. Habitação e Cidade. LOCONTE, W. (Coord.). São Paulo: Editora Atual (Espaço \& Debate), 1997, 79p.

MELLO, F. A. O. Análise do processo de formação da paisagem urbana do município de Viçosa, Minas Gerais. 2002. 103p. Dissertação (Mestrado em Ciência Florestal), Programa de Pós-Graduação em Engenharia Florestal, Universidade Federal de Viçosa, Viçosa, MG, 2002.

MORALES, S. M.; SOUZA, F. A. M. A gestão social da valorização do solo urbano nas práticas de regularização fundiária. In: Seminário Internacional de Curitiba, 3, 2010, Curitiba. Anais eletrônicos..., Curitiba, Universidade Positivo, 2010. Disponível em: <http://gpitufrgs.files.wordpress.com/2011/04/morales-selene-agestc3a3o-social-da- valorizac3a7c3a3o-do-solo-urbano-nas-prc3a1ticas-deregularizac3a7c3a3o-fundic3a1ria.pdf>. Acessado em: 04 nov. 2011.

O PASSADO COMPASSADO DE VIÇOSA (blog). Acesso rodoviário. Disponível em: $\quad<$ http://opassadocompassadodevicosa.blogspot.com.br/2013/01/abaixoassinado-museu- de-vicosa-ja.html>. Acessado em: 13 maio 2014.

PACHECO, A. O passado é para se refletir sobre ele: a Avenida P.H.Rolfs na década de 1960. Acervo do Tony Mello. Viçosa Cidade Aberta (blog). Disponível em: <http://vicosacidadeaberta.blogspot.com.br>. Acessado em: 11 de abr. 2015.

RIBEIRO FILHO, G. B. A formação do espaço construído: cidade e legislação urbanística em Viçosa, MG. 1997. 205p. Dissertação (Mestrado em Urbanismo), Programa de Pós-Graduação em Urbanismo, Universidade Federal do Rio de Janeiro - UFRJ, Rio de Janeiro, 1997. 
SANTOS, M. A evolução recente da população urbana, agrícola e rural. In: urbanização brasileira. São Paulo: Editora da Universidade de São Paulo, 2005, p. 31-36. 2014, 169p.

O espaço do cidadão. São Paulo: Editora da Universidade de São Paulo,

SILVA, A. H. L. A mobilidade urbana em questão: um olhar sobre a cidade de Viçosa-MG, 2011, 173p. Dissertação (Mestrado em Geografia), Programa de PósGraduação em Geografia, Universidade Estadual Paulista Júlio de Mesquita Filho UNESP, São Paulo, 2011. 